\title{
Schutz vor willkürlichen und diskriminierenden Entlassungen
}

Eine rechtsvergleichende Untersuchung zum Recht von Deutschland und British Columbia

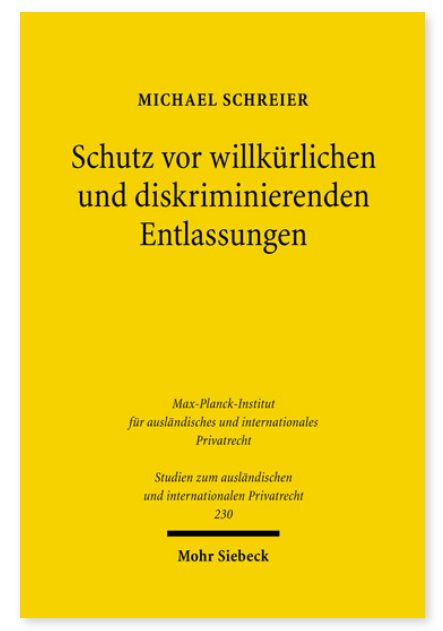

2009. XXV, 397 Seiten. StudIPR 230

ISBN 978-3-16-151415-9

DOI 10.1628/978-3-16-151415-9

eBook PDF $94,00 €$

ISBN 978-3-16-150230-9

fadengeheftete Broschur 94,00€
Kündigungsschutz ist eines der zentralen Themen, die immer wieder Diskussionen in Politik und Wissenschaft entfachen. Während auf der einen Seite die Beibehaltung des bisherigen Kündigungsschutzrechts oder dessen Stärkung befürwortet wird, wird auf der anderen Seite die Lockerung oder gar Abschaffung des Kündigungsschutzes in Deutschland diskutiert. Ähnlich kontroverse Diskussionen werden in Bezug auf das Antidiskriminierungsrecht geführt. Michael Schreier untersucht diese gegensätzlichen Ausgangspunkte rechtsvergleichend: Im Fokus steht der Schutz vor willkürlichen und diskriminierenden Kündigungen. Der Autor zeigt Unterschiede und Gemeinsamkeiten zwischen Kanada - am Beispiel der Provinz British Columbia - und Deutschland auf und leitet daraus Handlungsempfehlungen in Bezug auf das Kündigungsschutzgesetz und das Allgemeine Gleichbehandlungsgesetz an den deutschen Gesetzgeber ab.

Michael Schreier Geboren 1979; Studium der Rechtswissenschaft in Hamburg und Vancouver; Wissenschaftlicher Mitarbeiter am Lehrstuhl für ausländisches und internationales Privat- und Prozessrecht an der Universität Hamburg; 2009 Promotion; derzeit Rechtsanwalt in Hamburg.
Jetzt bestellen:

https://mohrsiebeck.com/buch/schutz-vor-willkuerlichen-und-diskriminierenden-entlassungen-9783161514159?no_cache=1 order@mohrsiebeck.com

Telefon: +49 (0)7071-923-17

Telefax: +49(0)7071-51104 